\title{
The global response to the threat of antimicrobial resistance and the important role of vaccines
}

\author{
Eric Utt ${ }^{\mathrm{a}, *}$ and Charles Wells ${ }^{\mathrm{b}}$ \\ a Science Policy and Advocacy Global Policy and International Public Affairs, Pfizer, New York, NY, USA \\ ${ }^{\mathrm{b}}$ Development Infectious Diseases TSU, Sanofi, Paris, France
}

\begin{abstract}
Antimicrobial resistance (AMR) has emerged as a significant threat to global health security and threatens the achievements of modern medicine. Research and successful development of new antibiotics, especially those with novel mechanisms of action vital to combat resistance, has slowed dramatically since the 1980s. Surveillance for AMR is highly variable globally with significant limitations in many countries impeding the ability to fully characterize the problem. Global efforts to control tuberculosis, malaria and HIV are facing increasing difficulties from the emergence of resistance. Similarly, bacteria causing some of the most common infections in communities or in hospitals such as Escherichia coli and Klebsiella pneumoniae have shown high levels of resistance to third generation cephalosporins requiring treatment with expensive carbapenems as last-resort. Additionally, Streptococcus pneumoniae has shown reduced susceptibility to penicillin in many regions, exceeding 50\% in some settings. The cost in lives from AMR over the next 40 years could go as high as 10 million per year with the cost to economic development as high as $\$ 3$ trillion per year if current trends continue. In addition to ensuring appropriate use of antibiotics and development of novel classes with new or enhanced mechanisms of action, many plans for the global response call for new vaccines as integral to the fight against AMR. Vaccines and antibiotics should be used together to produce synergistic gains in public health, and ultimately, vaccines will extend the clinical utility of antibiotics. The decrease in cases of invasive pneumococcal disease and decrease in prescriptions for antibiotics in some settings resulting from the introduction of broad access to, and utilization of conjugate vaccines for Streptococcus pneumoniae exemplifies the synergy that can be achieved in the fight against AMR.
\end{abstract}

Keywords: Antimicrobial resistance (AMR), antibiotics, antibiotic stewardship, antibiotic surveillance, vaccines, pneumococcus, S. pneumoniae, pharmaceutical industry, conjugated vaccines, Haemophilus influenzae

\section{Background}

Antimicrobial resistance (AMR) has emerged as a significant threat to global health security [1,2]. The problem is so serious that it threatens the achievements of modern medicine and a post-antibiotic era - in which common infections and minor injuries can kill - is a very real possibility for this century. Furthermore, the hard-won gains made in health and development, in particular those brought about

${ }^{*}$ Corresponding author: Eric Utt, Science Policy and Advocacy Global Policy and International Public Affairs, Pfizer, New York, NY, USA. E-mail: eric.a.utt@pfizer.com.

1389-2827/16/\$35.00 (c) 2016 - Network of Centres for Study of Pharmaceutical Law. All rights reserved This article is published online with Open Access and distributed under the terms of the Creative Commons Attribution Non-Commercial License (CC BY-NC 4.0). 
through the health-related Millennium Development Goals, are put at risk by increasing AMR and the sustainability of the public health response to many communicable diseases, including tuberculosis, malaria and HIV/AIDS is jeopardized [3].

AMR develops when a microorganism (bacteria, virus, parasite and fungus) no longer responds to a drug to which it was originally sensitive. Drugs for treating infections lose their effect because the microbes change; either they mutate or acquire genetic information from other microbes to develop resistance. The phenomenon is accelerated by use, and especially misuse, of antimicrobial medicines whereby resistant strains survive and aggregate. The problem can be further amplified when antimicrobial agents of substandard or falsified quality are procured and used by patients [4]. The situation translates into standard treatments no longer working infections are harder or impossible to control; the risk of the spread of infection to others is increased; illness and hospital stays are prolonged, with huge added economic and social costs [5]. By extension, the risk of death is greater - in some cases twice that of patients who have infections caused by non-resistant bacteria [6].

To make matters worse, the research and successful development of new antibiotics, especially those with novel mechanisms of action vital to combat resistance, has slowed dramatically since the 1980s [7,8]. For example, the number of antimicrobial agents approved by the FDA steadily dropped from 16 for the period $1983-$ 1987 down to three for the period 2008-2012. Though the number of approvals has increased somewhat since 2012, most of all antibiotics approved for use in patients today are derived from a limited number of types, or classes, of antibiotics that were discovered by the mid-1980s [9].

The lack of development of new classes of antibiotics is even more concerning than the decline of drug approvals because resistance to one antibiotic often leads to resistance to multiple antibiotics within the same class. Many factors have contributed to this decline, but it is primarily economic factors and regulatory constraints, including the rethinking of statistical principles of non-inferiority trial designs in the 1990s, which disproportionately has affected trials for antibacterial development [10].

\section{Current global burden of AMR}

In assessing the magnitude of AMR globally, the quality and capacity for surveillance and the available information is highly variable across countries and regions. Similarly, it is quite variable within the realm of infectious disease, with surveillance for resistance being more advanced for diseases like tuberculosis (TB) and malaria managed more as public health programs compared to resistance among bacteria that cause common healthcare associated and community-acquired infections [11]. In response, the World Health Organization (WHO) has taken important steps to characterize and measure the global magnitude of AMR with special emphasis on 
antibacterial resistance (ABR) to complement long-established surveillance efforts in TB and malaria and more recent efforts for HIV.

With respect to TB, malaria, and HIV, surveillance data demonstrate alarming trends related to AMR. For example, multidrug resistant TB (MDR-TB) is a growing problem and largely under-reported with the strong potential to compromise global control of TB; in settings such as India, patients with totally drug resistant TB have even been identified $[12,13]$. Related to malaria, foci of artemisinin resistance have been identified in multiple countries in Southeast Asia; further spread or emergence in other regions of this resistance could jeopardize important gains in malaria control made since 2000 [14]. Finally, increasing levels of transmitted anti-HIV drug resistance have been detected among patients starting antiretroviral treatment in low- and middle-income countries; available data suggest that $10 \%-17 \%$ of patients without prior history of ART in high income countries are infected with virus resistant to at least one antiretroviral drug [15-18].

With respect to the magnitude of ABR, for its first global report in 2014, WHO obtained information on resistance to antibacterial drugs commonly used to treat infections from more than 100 member states of the United Nations (UN) [19]. For this exercise, many gaps in information on pathogens of major public health importance, including gaps in surveillance, and a lack of standards for methodology, data sharing and coordination were identified. Nonetheless this was an important step forward on measuring the burden of ABR. As an overall finding of great concern, very high rates of resistance $(\geqslant 50 \%)$ have been observed in bacteria that cause common healthcare associated and community-acquired infections (e.g. urinary tract infection, pneumonia) in all of the WHO regions.

More specifically, the assessment focused on resistance in seven bacteria of international concern causing some of the most common infections in different settings such as the community, in hospitals or transmitted through the food chain including Escherichia coli, Klebsiella pneumoniae, Staphylococcus aureus, Streptococcus pneumonia, Nontyphoidal salmonella, Shigella species, Neisseria gonorrhea [20]. The main findings regarding antibacterial resistance from the WHO surveillance project from 2014 are included in Table 1. Of note, oral treatment options for urinary tract infections acquired in the community are becoming more limited. Additionally, expensive and more toxic second-line drugs requiring additional expensive monitoring are increasingly being required to effectively treat patients for a variety of infections and these drugs are often not widely available in many resource limited settings. Finally, resistance to drugs of last resort for some infections such as Neisseria gonorrhea has been widely detected globally.

Finally, WHO has identified that major gaps exist in surveillance and data sharing related to the emergence of antibacterial resistance in foodborne bacteria and its potential impact on both animal and human health. Surveillance is hampered by insufficient implementation of harmonized global standards. The multi-sector approach needed to contain antibacterial resistance includes improved integrated surveillance of resistance in bacteria carried by food-producing animals and in the food chain, and 
Table 1

Summary of findings from WHO's Antimicrobial resistance: Global report on surveillance 2014 focused on seven bacteria of international concern causing common infections [95] ${ }^{\dagger}$

\begin{tabular}{|c|c|c|}
\hline Bacterial agent & Finding & Implication \\
\hline Escherichia coli & $\begin{array}{l}\text { - High } \% \text { of resistance to } 3^{\text {rd }} \text { genera- } \\
\text { tion cephalosporins }\end{array}$ & $\begin{array}{l}\text { - Treatment of severe infections in } \\
\text { many settings must rely on expen- } \\
\text { sive carbapenems as last-resort } \\
\text { - Limited options for oral agents to } \\
\text { treat community acquired infections } \\
\text { (UTIs) }\end{array}$ \\
\hline $\begin{array}{l}\text { Klebsiella } \\
\text { pneumoniae }\end{array}$ & $\begin{array}{l}\text { - High } \% \text { of resistance to } 3^{\text {rd }} \text { genera- } \\
\text { tion cephalosporins } \\
\text { - Resistant to carbapenems in most } \\
\text { countries; resistance up to } 54 \% \text { in } \\
\text { some settings }\end{array}$ & $\begin{array}{l}\text { - Treatment of severe infections in } \\
\text { many settings must rely on expen- } \\
\text { sive carbapenems as last-resort }\end{array}$ \\
\hline $\begin{array}{l}\text { Staphylococcus } \\
\text { aureus }\end{array}$ & $\begin{array}{l}\text { - High rates of methicillin-resistant } \\
\text { (MRSA) among patients with se- } \\
\text { vere skin and wound infections }\end{array}$ & $\begin{array}{l}\text { - Expensive } 2^{\text {nd }} \text {-line drugs needed } \\
\text { for treatment with need to monitor } \\
\text { for severe side-effects } \\
\text { - Standard prophylaxis with } 1^{\text {st }} \text {-line } \\
\text { drugs for orthopaedic and other sur- } \\
\text { gical procedures with limited effect }\end{array}$ \\
\hline $\begin{array}{l}\text { Streptococcus } \\
\text { pneumoniae }\end{array}$ & $\begin{array}{l}\text { - Reduced susceptibility to penicillin } \\
\text { detected in all WHO regions; ex- } \\
\text { ceeded 50\% in some reports } \\
\text { - Limited comparability of laboratory } \\
\text { standards and variation in how re- } \\
\text { duced susceptibility is reported }\end{array}$ & $\begin{array}{l}\text { - Extent of problem and impact on } \\
\text { patients not clear given laboratory } \\
\text { issues } \\
\text { - Because invasive disease (e.g. pneu- } \\
\text { monia and meningitis) is common } \\
\text { and serious in children and elderly, } \\
\text { better monitoring of resistance is ur- } \\
\text { gently needed }\end{array}$ \\
\hline $\begin{array}{l}\text { Nontyphoidal } \\
\text { salmonella } \\
\text { (NTS) and } \\
\text { shigella species }\end{array}$ & $\begin{array}{l}\text { - Fluroquinolone resistance compara- } \\
\text { tively lower than in Escherichia coli }\end{array}$ & $\begin{array}{l}\text { - Some reports of high resistance in } \\
\text { NTS of great concern because re- } \\
\text { sistant strains associated with worse } \\
\text { patient outcomes }\end{array}$ \\
\hline $\begin{array}{l}\text { Neisseria } \\
\text { gonorrhea }\end{array}$ & $\begin{array}{l}\text { - Decreased susceptibility to third- } \\
\text { generation cephalosporins (last re- } \\
\text { sort treatment) verified in } 36 \text { coun- } \\
\text { tries and growing problem }\end{array}$ & $\begin{array}{l}\text { - Potential for global untreatable } \\
\text { venereal disease }\end{array}$ \\
\hline
\end{tabular}

${ }^{\dagger}$ Information compiled from WHO AMR Report, 2014 - World Health Organization (2014) Antimicrobial resistance: global report on surveillance 2014. http://www.who.int/drugresistance/documents/surveil lancereport/en/.

prompt sharing of data. Integrated surveillance systems would enable comparison of data from food-producing animals, food products and humans [21].

\section{Global economic impact of AMR}

Antibiotic-resistant infections add considerable and avoidable costs to the already over-burdened healthcare systems. In most cases, antibiotic-resistant infections re- 
Table 2

Estimated annual costs from AMR in three regions [96]

\begin{tabular}{|c|c|c|c|}
\hline & EU & Thailand & US \\
\hline Population & 500 million & 70 million & 310 million \\
\hline $\begin{array}{l}\text { People infected } \\
\text { with bacteria } \\
\text { with AMR }\end{array}$ & - & - & $\sim 2,000,000$ \\
\hline $\begin{array}{l}\text { Deaths/year from } \\
\text { AMR }\end{array}$ & 25,000 & $>38,000$ & $>23,000$ \\
\hline $\begin{array}{l}\text { Added morbidity } \\
\text { from AMR }\end{array}$ & $\begin{array}{l}2.5 \text { million extra hospital } \\
\text { days }\end{array}$ & $\begin{array}{l}>3.2 \text { million hospital } \\
\text { days }\end{array}$ & $>2.0$ million illnesses \\
\hline $\begin{array}{l}\text { Overall societal } \\
\text { costs }\end{array}$ & $\begin{array}{l}\text { - } € 900 \text { million, hosp. } \\
\text { days } \\
\text { - Approx. } € 1.5 \text { billion } \\
\text { per year }\end{array}$ & $\begin{array}{l}\text { - } \$ 84.6-202.8 \text { million, } \\
\text { direct } \\
\text { - } \$ 1.3 \text { billion, indirect }\end{array}$ & $\begin{array}{l}\text { - Up to } \$ 20 \text { billion } \\
\text { direct } \\
\text { - Up to } \$ 35 \text { billion } \\
\text { indirect }\end{array}$ \\
\hline Source & ECDC 2007 [97] & Pumart et al. 2012 [98] & CDC, 2013 [99] \\
\hline
\end{tabular}

‡Information compiled from WHO AMR Report, 2014 - World Health Organization (2014) Antimicrobial resistance: global report on surveillance 2014. http://www.who.int/drugresistance/documents/ surveillancereport/en/ and slide deck on report provided in public domain by WHO.

quire prolonged and costlier treatments, extended hospital stays, and additional doctor visits and healthcare use resulting in greater disability and death compared with infections that are easily treatable with antibiotics.

Sources available from some countries help to illustrate the current situation in terms of the economic impact of AMR as a baseline for gauging what the future might hold (see Table 2). In the European Union (EU) alone, the additional burden posed by resistance every year, focusing only on a limited group of healthcareassociated bacterial infections, is in the range of 2.5 million hospital days, 25,000 deaths and economic losses on the order of $€ 1.5$ billion due to extra healthcare costs and productivity losses [22]. According to a recent study in Thailand, in 2010 antimicrobial resistance was responsible for at least 3.2 million extra hospitalization days and 38,481 deaths, and for losses amounting to \$84.6-\$202.8 million in direct medical costs and more than $\$ 1.3$ billion in indirect costs [23] In the United States (US), where approximately 23,000 people die each year as a direct result of AMR, estimates for the total economic cost of antibiotic resistance vary but have ranged as high as $\$ 20$ billion in excess direct healthcare costs, with additional costs from lost productivity as high as $\$ 35$ billion a year (2008 dollars) [24-26].

From the global perspective, the Independent Review on AMR commissioned by the Government of the United Kingdom (UK) and led by the renowned economist Jim O'Neill commissioned a study in 2014 to estimate the global costs of AMR until 2050 in the absence of any progress in addressing the challenge [27]. The results from this analysis demonstrated that if current trends persist resulting in increasing morbidity and mortality related to AMR, the costs in terms of healthcare, loss of life, productivity, and by extension, global economic development are potentially staggering at orders of magnitude higher than seen at present and render AMR as an urgent public health crisis requiring immediate intervention [28]. 
From the commissioned analysis, based on various conservative assumptions, on average over a 40-year span, the world GDP loss runs between $\$ 53$ billion to $\$ 3$ trillion per year [29]. In some scenarios, up to 10 million lives per year could be lost by 2050 (up from 700,000 estimated deaths presently occurring worldwide) and a cumulative $\$ 100$ trillion of economic output are at risk due to the rise of drugresistant infections if proactive solutions are not put into place now to slow down the rise of drug resistance. As with all forecasts of this sort, it is possible that the analysis represents an overestimate of the scale of the problem; however, it is even more likely the analysis underestimates the potential future impact as the secondary effects of antibiotics losing their effectiveness were not even considered [30]. Additionally, new forms of resistance have already emerged much sooner than expected, such as the highly disturbing discovery of transferable colistin resistance, reported in late 2015 [31].

\section{The need for stewardship}

A major contributor to the emergence of AMR has been poor management over time of the use of existing antimicrobial agents. The problem is pervasive in both developed countries and those of constrained resources. Demand for these agents is poorly managed. Large quantities of antimicrobials are used globally on patients who do not need them, while others who need them do not have access. Antibiotic prescriptions are often not informed by up to date surveillance, and rapid diagnostic testing that could guide prescribing more effectively is limited in many settings.

Some research from the US has shown that as much as $50 \%$ of the time antibiotics are prescribed when they are not needed or they are misused which promotes antibiotic resistance [32]. In European countries, systemic antibiotics are prescribed in greatest volume to ambulatory patients, mostly for respiratory tract infections [33]. Recent studies from Eastern Europe have identified the inappropriate use of antibiotics for viral infections of the respiratory tract and sub-therapeutic dosing as common in both hospital and ambulatory settings (in one published report correct dosing was reported in $38 \%$ of outpatient and $74 \%$ of medical charts of children with respiratory infections in hospital that were reviewed) [34,35] In Thailand, unnecessary use of antibiotics is seen among both health professionals and the public [36-38] One study in a tertiary care hospital revealed that only $7.9 \%$ of the upper respiratory tract infections (URIs) in the facility were caused by bacteria $[39,40]$ Despite this, in Thailand most URIs are treated with antibiotics by hospitals, health centers, drug stores and patients themselves [41-45]. Liberal use of antibiotics endangers the health of patients without observable clinical benefits, since it neither reduces the rate of complications nor quickens recovery when the illness is caused by a virus [46,47]. Finally, the full extent of the wide usage of antibiotics in agriculture is unknown due to a lack of surveillance, and antibiotics that are vital for human health are not restricted from usage in animals. 


\section{Examples of stewardship}

Increasing awareness of antimicrobial resistance and promoting the rational use of antibiotics among prescribers and the general public are key to combating the unnecessary use of these drugs [48,49]. Antibiotics are a limited resource. The more that antibiotics are used today, the less likely they will still be effective in the future. Therefore, doctors and other healthcare professionals around the world are increasingly adopting the principles of responsible antibiotic use, often called antibiotic stewardship. Stewardship is a commitment to always use antibiotics only when they are necessary to treat, and in some cases prevent, disease; to choose the right antibiotics; and to administer them in the right way in every case [50]. Effective stewardship ensures that every patient gets the maximum benefit from the antibiotics, avoids unnecessary harm from allergic reactions and side effects, and helps preserve the life-saving potential of these drugs for the future. Efforts to improve the responsible use of antibiotics have not only demonstrated these benefits but have also been shown to improve outcomes and save healthcare facilities money in pharmacy costs.

One global example of antibiotic stewardship that is working well is the Green Light Committee (GLC) Initiative undertaken to combat the growing epidemic of MDR-TB [51]. The initiative was established as a public-private partnership nearly 20 years ago by WHO in response to difficulties experienced by countries in finding and funding stable supplies of high-quality anti-TB drugs and to address the growing emergence of resistance resulting from poor quality drugs being used in many countries. The goal was to promote access to and rational use of second-line anti-TB drugs for the treatment of MDR-TB. Stakeholders included academic institutions, civil society organizations, bilateral donors, Governments, and the private sector. The effectiveness of the partnership emerged in part from its ability to link access, rational use, technical assistance, and policy development. Data from research design to evaluate the mechanism and its guiding principles demonstrate the impact and effectiveness of the initiative since its launch. In one large multinational prospective cohort study evaluating treatment approaches and comparing outcomes for MDR-TB patients in countries using the GLC mechanism versus those that did not showed that treatment success among patients in countries using the mechanism was substantially greater [83\% versus $60 \%$, respectively; $(p<0.001)]$ and by extension the initiative was shown to have reduced further emergence of anti-TB drug resistance [52]. The GLC mechanism may be useful in the development of other partnerships needed in the rational allocation of resources and tools for combating AMR more broadly.

Other examples at the country level of important stewardship programmes that have been launched in developed countries include "Strama" in Sweden [53]; the Get Smart: know when antibiotics work programme of the US Centers for Disease Control and Prevention [54], and several national public campaigns in Europe [55,56]. In the context of country settings of more limited resources, the Antibiotics Smart Use (ASU) program was introduced in Thailand in 2007 as an innovative model to 
promote the rational use of medicines and counteract antimicrobial resistance building on interventions undertaken prior to 2007 that had only been partially successful and it is showing great promise [57].

\section{Global response}

In 2014, the UK Prime Minister commissioned a wide reaching independent review [58], led by the internationally renowned economist Jim O'Neill and cofounded and hosted by the world's second largest medical research foundation, the Wellcome Trust, to explore the economic issues surrounding antimicrobial resistance. After 18 months of consultation, Jim O'Neill presented ten key elements to tackle AMR in a global way in May 2016 including public awareness, sanitation and hygiene, antibiotics in agriculture and the environment, vaccines and alternatives, surveillance, rapid diagnostics, human capital, new drugs, global innovation fund, and an international coalition for action [59].

In 2014, US President Barack Obama signed an Executive Order directing key Federal departments and agencies to take action to combat the rise of antibioticresistant bacteria [60]. The US Administration also released its National Strategy on Combating Antibiotic-Resistant Bacteria. In addition, the President's Council of Advisors on Science and Technology (PCAST) released a related report on Combating Antibiotic Resistance. In addition, the Biomedical Advanced Research and Development Authority (BARDA) established the Broad Spectrum Antimicrobials (BSA) Program in April 2010 to boost the development of novel antibacterial and antiviral drugs to treat or prevent diseases caused by biological threats [61].

In Europe, the Innovative Medicines Initiative's (IMI) public-private partnership model is based on a partnership between the European Commission and the European Federation of Pharmaceutical Industries and Associations (EFPIA). In March 2012, IMI launched its first call for proposals under the 'New Drugs for Bad Bugs' (ND4BB) program, a major public-private partnership effort to address bottlenecks in the discovery and development of new antibiotics. http://www.who.int/phi/imple mentation/1_infobrief_innovative_medicines_initiative_ND4BB_models_of_collab oration.pdf [62]. In October 2014, the ND4BB launched the DRIVE-AB Project. DRIVE-AB aims at developing options for novel economic models of antibiotic research and development (R\&D) and responsible use of antibiotics.

In January 2016, a Declaration by the Pharmaceutical, Biotechnology and Diagnostics Industries on Combating Antimicrobial Resistance called on governments to work with industry to develop new and alternative market structures that provide more dependable and sustainable market models for antibiotics, and to commit the funds needed to implement them [63]. The Declaration was signed by 100 pharmaceutical, biotech and diagnostics companies and 13 associations. It sets commitments to further action on drug resistance by its signatories, across three broad areas: reducing the development of drug resistance, increasing investment in $R \& D$ that meets global public health needs, and improving access to high-quality antibiotics for all. 
In the last two years, AMR has gained prominence on the agenda of G7 leaders who have publically referred to this issue as one of the most important global threats. During the German presidency, AMR was mentioned in the leaders' declaration from Schloss Elmau summit in June 2015 [64] and the Berlin G7 Health Ministers declaration in October 2015 [65]. Germany's engagement on AMR was continued under the Japanese presidency with the launch in May 2016 of the G7 Ise-Shima Vision for Global Health [66], the vision is composed of four pillars:

1. Reinforcing the global health architecture to strengthen responses to public health emergencies.

2. Attaining UHC with strong health systems and better preparedness for public health emergencies.

3. AMR.

4. $R \& D$ and innovation.

Finally, for the first time, the G20 will discuss a health issue; the Chinese G20 summit which will be held in September 2016 will discuss global solutions to combat AMR.

\section{WHO engagement}

On May 2015, the World Health Assembly (WHA) of the WHO endorsed the AMR Global Action Plan (GAP). The GAP is composed of five strategic objectives:

1. Objective 1: Improve awareness and understanding of antimicrobial resistance through effective communication, education and training.

2. Objective 2: Strengthen the knowledge and evidence base through surveillance and research.

3. Objective 3: Reduce the incidence of infection through effective sanitation, hygiene and infection prevention measures.

4. Objective 4: Optimize the use of antimicrobial medicines in human and animal health.

5. Objective 5: Develop the economic case for sustainable investment that takes account of the needs of all countries, and increase investment in new medicines, diagnostic tools, vaccines and other interventions.

The WHA also called Members States to develop their own national action plans based on the GAP and report on progress at the WHO WHA in May 2017. The WHO also released last April a worldwide country situation analysis on AMR which showed that only 34 out of 133 participating in the survey have a comprehensive national plan to fight resistance to antibiotics and other antimicrobial medicines. The situation varies sensitively depending on the region. After the adoption of the GAP, countries are now entering an "implementation phase": some countries are already well advanced in the development of their action plans, while others need support and guidance. 
As a follow-up to the request made in resolution WHA68.7 [67], WHO is in the process of establishing a global development and stewardship framework to support the development, control, distribution and appropriate use of new antimicrobial medicines, diagnostic tools, vaccines and other interventions. The framework should also provide guidance to member states preserving existing antimicrobial medicines, and promote affordable access to existing and new antimicrobial medicines and diagnostic tools.

Finally, the UN Secretary General and the WHO Director General will co-host a High Level Meeting (HLM) on AMR in September 2016 in the margins of the UN General Assembly. The meeting aims at increasing political awareness, engagement and leadership on antimicrobial resistance.

With respect to the response to AMR by the private sector, in the Declaration by the Pharmaceutical, Biotechnology and Diagnostics Industries on Combating Antimicrobial Resistance, pharmaceutical companies expressed the commitment to work to reduce the development of AMR through its support to continued education for clinical professionals on appropriate use and strengthened infection control via improved hygiene, vaccination, and preventive treatments and through measures to reduce environmental pollution from antibiotics, along with a 'one health' approach towards prudent and responsible use, including a global reduction of unnecessary antibiotic use in livestock.

\section{Role of vaccines in the global fight against AMR}

In the face of the alarming trends in AMR and the projected economic impact, in addition to ensuring the appropriate use of antibiotics and the development of novel classes with new or enhanced mechanisms of action, vaccines are critical tools in the fight against infectious diseases and AMR. Vaccines can prevent infections and therefore lower the demand for therapeutic treatment with antimicrobials and, in turn, reduce disease with antimicrobial strains and also attenuate further increases in drug resistance. Vaccines protect the vaccinated individual by direct immunization and can protect others through indirect immunization (assuming the overall vaccination rate is high enough). Vaccines and antibiotics should be used as complementary tools to produce synergistic gains in public health. Ultimately, vaccines can extend the clinical utility of antibiotics by reducing infections and limiting their transmission, this impact in turn allows antimicrobials to be used more sparingly and under closer supervision. For example, a Finnish study found that the introduction of a pneumococcal vaccine covering more strains reduced antibiotic purchases by $8 \%$ [68].

Nevertheless, this positive synergy can be reversed if either component - vaccines or drugs - are not used well. When compliance with vaccine schedules is compromised and/or adherence to policy recommendations is rejected, optimal prevention of infection is not achieved, and infection rates may increase. As a result, more and more antimicrobials will need to be used. Even when the antimicrobials are used 
carefully, emergence of resistant pathogens still occurs, but when they are used indiscriminately, as is too often the case, then the problem is made worse. From an investment standpoint, if vaccines are underutilized, there is less incentive to develop new ones; and if antimicrobials are over utilized, their effective commercial life becomes shorter and there is less incentive to develop replacements. Better public health policies to emphasize increased compliance with vaccine schedules and better stewardship of antibiotic drugs are essential. From a public health policy perspective, the recent focus on the failure of markets to ensure access, conservation, and innovation in the antimicrobial drug marketplace should be broadened to include incentives for vaccines that can help meet the end goal of reducing the need for antimicrobial treatment while making sure the drugs are effective when they are needed [69]. The role of national vaccination programs were reviewed in a recent study [70]. That study showed decreased antibiotic use associated with initiation of vaccination programs or increased uptake of available vaccines (e.g. influenza and pneumococcal vaccines). Reductions in antibiotic use ranged from 5 to $10 \%$ in randomized controlled trials, to a relative reduction of disease incidence of $64 \%$ in epidemiological studies. This suggests that vaccination programs may reduce antibiotic utilization and, consequently, antibiotic resistance.

\section{Value of conjugated vaccine technologies}

In the battle against evolving resistance, conjugate vaccine technology is especially valuable. This vaccine technology has enabled the production of several commercially and medically important vaccines (various capsule types of Haemophilus Influenzae, N. meningitidis and Streptococcus pneumoniae. The potential to add protection against additional strains (e.g. PV7 to PV13 in the case of Streptococcus pneumoniae) is ideally suited to the realities of infectious diseases. As additional antibiotic resistance strains emerge, conjugate technology will allow the development of new safe and protective vaccines against these strains.

There are several examples of available vaccines having a positive impact on preventing emergence of antibiotic resistance in targeted bacteria. Infections caused by the gram positive cocci Streptococcus pneumoniae are frequent causes of morbidity and mortality worldwide. Infections caused by Streptococcus pneumoniae include otitis media and sinusitis, as well as more severe invasive disease such as pneumonia, sepsis, and meningitis (invasive pneumococcal disease or IPD). The WHO estimates that more than 1.6 million people - including more than 800,000 children under five years old - die every year from pneumococcal infections [71]. This also includes elderly persons and those with underlying diseases who are also susceptible to severe infections caused by Streptococcus pneumoniae [72].

In the year 2000, pneumococcal conjugate vaccines (PCVs) were introduced in the US; they have since then been introduced in the national childhood vaccination programs in many countries worldwide. Since its introduction to US infants and 
toddlers, heptavalent pneumococcal conjugate vaccine (PCV7), licensed in the US as a four-dose schedule (a three-dose primary series at two, four, and six months with a booster dose at 12-15 months, aptly named a " $3+1$ schedule") [73], has virtually eliminated US childhood IPD caused by the seven pneumococcal serotypes contained in PCV7 [74]. The subsequent introduction of 13-valent PCV (PCV13) in 2010 added protection against an additional six pneumococcal serotypes that: 1) were not previously covered by PCV7; and 2) become increasingly prevalent after PCV7 was introduced [75].

Zhou et al. reported that the use of PCV7 against drug-resistant Streptococcus pneumoniae (DRSP) has led to a decrease in prescriptions for antibiotics, which is likely to lead to less antibiotic use [76]. This well-documented case suggests the role vaccines can play in decreasing antibiotic resistant infections. Additionally, Dagan et al reported that use of PCVs has led to the reduction of DRSP [77]. Whitney et al reported that the PCV not only reduces the incidence of invasive antibiotic-resistant pneumococcal infections in young children receiving the vaccine, but it also reduces transmission of these strains to their younger siblings and to adults [78]. Klugman et al. showed in a 2001 study that PCVs have shown a high degree of success in preventing pneumococcal bacteremia in children [79]. They also reduce the acquisition of carriage of vaccine serotypes in the nasopharynx, and reduce otitis media caused by those serotypes. Klugman also stated that PCVs interrupt the transmission of antibiotic-resistant pneumococci and thus decrease the burden of antibiotic resistance in immunized children and in their contacts. Kyaw et al reported in a 2006 study that the rate of antibiotic-resistant invasive pneumococcal infections decreased in young children and older persons after the introduction of the conjugate vaccine. While there was an increase in infections caused by serotypes not included in the vaccine, the net effect was a reduction in number of infections and lower use of antibiotics [80].

The first PCV (PCV7) was licensed in the US for use in infants and children in 2000. A recent US study showed that between 1998 and 2008, there were a 64\% decrease in antibiotic-resistant pneumococci among children and a $45 \%$ decrease among adults over 65 [81]. Data from a South African study showed that since that country's introduction of a PCV in 2009, in addition to the expected reduction in the overall incidence of invasive pneumococcal disease by about two-thirds in infants (the age group vaccinated) and in adults, there was also a reduction in penicillinresistant infections in both vaccinated groups [82]. This is the first time such benefits have been observed outside the developed world.

Thus the evidence is mounting that vaccines can serve as an effective tool for reducing disease caused by drug-resistant strains as a complement to rational use of antibiotics. Unfortunately, continued widespread antibiotic use has resulted in an increase in disease by serotypes not covered by the PCV7 vaccine, such as serotype $19 \mathrm{~A}$, which has become the leading cause of the remaining invasive pneumococcal infection. The new PCV13 was approved in 2010 and was developed to provide 
immunity against this and other serotypes not covered by PCV7. Thus, we must continue to rely on the effectiveness of existing and new antibiotics to control infections caused by the emergence of new strains not covered by existing vaccines.

PCV13 provides an opportunity to prevent even more resistant infections of pneumococcal disease. In a recent study done by the CDC an examination of the US Streptococcus pneumoniae isolates from 10 Active Bacterial Core Surveillance sites demonstrated a decrease of multidrug - resistance in the PCV13 covered strains [83]. The study specifically showed that there was a $93 \%$ and $86 \%$ reduction of isolates that were resistant to either single or multiple antibiotics, respectively. The study also showed an increase in antibiotic resistance for Streptococcus pneumoniae isolates that were not covered by the vaccine.

Strains of the gram negative bacillus Haemophilus influenzae are found as both respiratory tract commensals and respiratory and invasive pathogens. The major diseases caused by Haemophilus influenzae include childhood pneumonia, meningitis, and bacteremia, (primarily caused by type $b$ strains), and community-acquired pneumonia (CAP) in adults, acute otitis media (AOM), acute sinusitis, and acute exacerbations of chronic bronchitis (AECB).

Prior to introduction of Haemophilus influenzae type b (Hib) vaccines in 1977, meningitis and pneumonia caused by Hib was responsible worldwide for roughly three million serious infections and 386,000 deaths per year. Furthermore almost $95 \%$ of these infections, and $98 \%$ of deaths, occurred in developing countries [84].

Haemophilus influenzae are known to contain resistance to several clinically relevant antibiotics including-lactam antibiotics, macrolides, ketolides, azalides, quinolones, tetracyclines, chloramphenicol, trimethoprim and sulfamethoxazole [85]. Widespread and systematic vaccination with the Hib vaccine has virtually eliminated Hib disease in most industrialized nations, and the Hib vaccine had been introduced in 192 countries by the end of 2014 [86].

With respect to the impact of Hib vaccination on antibiotic resistance, several studies have seen a positive correlation between use of the Hib vaccine and a reduction in resistance to one or more antibiotics. In a large 10-year Italian study, investigators demonstrated a marked $50 \%$ decrease in $\beta$-lactamase - mediated resistance to ampicillin and related $\beta$-lactam antibiotics [87]. Similarly, a Spanish study showed that antibiotic resistance in Haemophilus influenzae decreased in Spain from 1997 to 2007, due to a Hib vaccine - related reduction in the use of several antibiotics [88]. Citing one example from that study, while community consumption of trimethoprim-sulfamethoxazole decreased by $54 \%$, resistance to those antibiotics decreased from 50 to $34.9 \%$ [89]. A US study also demonstrated a decrease in prevalence of $\beta$-lactamase producing respiratory tract isolates of Haemophilus influenzae in the US [90]. Finally, a longitudinal European surveillance study showed that the overall resistance of Haemophilus influenzae to amoxicillin in Europe to decline (1997/98 and 2002/03), due to a decreasing number of $\beta$-lactamase - producing strains [91]. 
In addition to the demonstrated, positive effects that bacterial vaccines have on reducing antibiotic resistance, a similar effect is seen with certain viral vaccines, especially in terms of secondary infections. For example in the case of primary viral influenza infections, we often see bacterial respiratory infections due to associated Streptococcus pneumoniae and Haemophilus influenzae, especially in the elderly. While it is within the scope of practice to prescribe antibiotics to treat these infections, prior immunization with the viral influenza vaccine can prevent secondary bacterial infections and thereby reduce the need for antibiotic usage. For example, in a Canadian study, the introduction of universal influenza vaccination, resulted in a $64 \%$ decrease in influenza associated respiratory disease antimicrobial prescriptions in the province of Ontario [92]. This effect has been corroborated by others [93].

In the case of varicella virus infection (chickenpox), secondary infection by Staphylococcus aureus is common and causes an estimated 150,000 infectious every year, each requiring the administration of antibiotics [94]. The same report also reported a $42.9 \%$ to $47.0 \%$ reduction in days of antibiotic use after influenza vaccination in healthy working adults. More widespread usage of the varicella vaccine would be expected to reduce secondary infections caused my Staphylococcus aureus, thus reducing the need for antibiotics administration against this often resistant pathogen.

\section{Conclusions}

AMR represent a major threat to global health security with the potential to have devastating effects on global economic development. If current trends in AMR continue unchecked, upwards of 10 million lives per year and trillions of dollars of losses to the global economy could occur annually by 2050 . Surveillance that generates reliable data is the essential basis of sound global strategies and public health actions to contain AMR, and is urgently needed around the world. Furthermore, the supply of new anti-microbial agents is insufficient to keep up with the increase in drug resistance as older agents are used more widely and non-judiciously and microbes further evolve to resist them. As no truly new class of antibiotics has been developed for decades, new drugs to replace the ones that are not working anymore because of resistance are urgently needed. Stewardship programs to avoid non-evidence based use of antibiotics and to promote appropriate dosing are key to preventing further emergence of antibiotic resistance and poor outcomes for patients. Countries must review carefully how they buy and price antibiotics, to reward innovative new drugs without encouraging unnecessary use of new antibiotics.

Vaccines can prevent infections and lower the demand for therapeutic treatments leading to reduced usage of antimicrobials and in turn slowing the rise of drug resistance. The experience with vaccination programs for Streptococcus pneumoniae and Haemophilus influenzae are prime examples of what can be achieved. By reducing infections and limiting their transmission, vaccines allow drugs to be used 
more sparingly and under closer supervision thereby extending their utility. Therefore, vaccines should be used more widely and used together with antibiotics to produce synergistic gains in public health. As such, vaccine development for infectious diseases is a critical part of the solution to AMR and should be eligible for the same incentives being recommended for antibiotic development.

\section{References}

[1] United Nations General Assembly - Seventieth session, Agenda item 125. A/RES/70/183 Global health and foreign policy: strengthening the management of international health crises http://www. un.org/en/ga/search/view_doc.asp?symbol=A/RES/70/183.

[2] SIXTY-SEVENTH WORLD HEALTH ASSEMBLY WHA67.25; Agenda item 16.5 24 May 2014, Antimicrobial resistance. http://apps.who.int/gb/ebwha/pdf_files/WHA67/A67_R25-en.pdf.

[3] World Health Organization, document WHA64/2011/REC/1. United Nations. Millennium Development Goals indicators. United Nations; 2008 http://mdgs.un.org/unsd/mdg/Host.aspx?Content= indicators/officiallist.htm.

[4] R. Bate, P. Jensen, K. Hess, L. Mooney and J. Milligan, Substandard and falsified anti-tuberculosis drugs: A preliminary field analysis, Int J Tuberc Lung Dis. 17(3) (2013), 308-311. doi: 10.5588/ ijtld.12.0355.

[5] R.R. Roberts et al., Hospital and Societal Costs of Antimicrobial-Resistant Infections in a Chicago Teaching Hospital: Implications for Antibiotic Stewardship, CID 49 (2009), 1175-1184.

[6] WHO AMR Report, 2014 - World Health Organization (2014a) Antimicrobial resistance: global report on surveillance 2014. Available from http://www.who.int/drugresistance/documents/surveil lancereport/en/.

[7] The Pew Charitable Trusts, Infectious Diseases Society of America, Pharmaceutical Research and Manufacturers of America, "Reviving the Pipeline of Life-Saving Antibiotics: Exploring Solutions to Spur Innovation,” conference proceedings, Sept. 22, 2011, Washington, http://www.idsociety. org/uploadedFiles/IDSA/Policy_and_Advocacy/Current_Topics_and_Issues/Advancing_Product_ Research_and_Development/Bad_Bugs_No_Drugs/Press_Releases/Conference\%20Proceedings_ FINAL_4.11.12.pdf.

[8] D.M. Shlaes, D. Sahm, C. Opiela and B. Spellberg, The FDA reboot of antibiotic development, Antimicrob Agents Chemother 57(10) (2013), 4605-4507. doi: 10.1128/AAC.01277-13. Epub 2013 Jul 29.

[9] Silver, "Challenges of Antibacterial Discovery," 71-109; Tommasi et al., "SKAPEing the Labyrinth of Antibacterial Discovery," 529-542.

[10] Despite Growing Crisis, Few New Antibiotics Are in Pipeline. Clin Infect Dis. Published online April 18, 2013. http://cid.oxfordjournals.org.proxy1.athensams.net/content/early/2013/04/16/cid. cit152.full.

[11] WHO AMR Report, 2014 - World Health Organization (2014a) Antimicrobial resistance: global report on surveillance 2014. http://www.who.int/drugresistance/documents/surveillancereport/en/.

[12] World Health Organization. Global Tuberculosis Report 2015. WHO/HTM/TB/2015.22.

[13] Z.F. Udwadia, R.A. Amale, K.K. Ajbani and C. Rodrigues, Totally drug-resistant tuberculosis in India, Clin Infect Dis. 54(4) (2012), 579-581. doi: 10.1093/cid/cir889. Epub 2011 Dec 21.

[14] World Health Organization. World Malaria Report 2015 http://www.who.int/malaria/publica tions/world_malaria_report_2015/en.

[15] WHO HIV drug resistance report. Geneva, World Health Organization (WHO), 2012. (http:// apps.who.int/iris/bitstream/10665/75183/1/9789241503938_eng.pdf).

[16] L. Wittkop, H.F. Gunthard, F. de Wolf, D. Dunn, A. Cozzi-Lepri, A. de Luca et al., Effect of transmitted drug resistance on virological and immunological response to initial combination antiretroviral therapy for HIV (EuroCoord-CHAIN joint project): a European multicohort study, Lancet Infect Dis. 11(5) (2011), 363-371. doi: 10.1016/S1473-3099(11)70032-9. 
[17] R.L. Hamers, R. Schuurman, K.C. Sigaloff, C.L. Wallis, C. Kityo, M. Siwale et al., PharmAccess African Studies to Evaluate Resistance (PASER) Investigators. Effect of pretreatment HIV-1 drug resistance on immunological, virological, and drug-resistance outcomes of first-line antiretroviral treatment in sub-Saharan Africa: A multicentre cohort study, Lancet Infect Dis. 12(4) (2012), 307317. doi: 10.1016/S1473-3099(11)70255-9.

[18] WHO AMR Report, 2014 - World Health Organization (2014a) Antimicrobial resistance: global report on surveillance 2014. http://www.who.int/drugresistance/documents/surveillancereport/en/.

[19] WHO AMR Report, 2014 - World Health Organization (2014a) Antimicrobial resistance: global report on surveillance 2014. http://www.who.int/drugresistance/documents/surveillancereport/en/.

[20] WHO AMR Report, 2014 - World Health Organization (2014a) Antimicrobial resistance: global report on surveillance 2014. http://www.who.int/drugresistance/documents/surveillancereport/en/.

[21] Tackling antibiotic resistance from a food safety perspective in Europe. http://www.euro.who.int/ _data/assets/pdf_file/0005/136454/e94889.pdf.

[22] European Commission. EU research on antimicrobial resistance: EU projects 2007-2010. Brussels: UC; 2011. Available from: http://ec.europa.eu/research/health/infectious-diseases/antimicrobialdrug-resistance/pdf/eu-research-on-antimicrobial-resistance_en.pdf.

[23] P. Pumart, T. Phodha, V. Thamlikitkul, A. Riewpaiboon, P. Prakongsai and S. Limwattananon, Health and economic impacts of antimicrobial resistance in Thailand, J Health Systems Res 6 (2012), 352-360.

[24] Centers for Disease Control and Prevention. Antibiotic Resistance Threats, 2013.

[25] R.R. Roberts, B. Hota, I. Ahmad et al., Hospital and societal costs of antimicrobial-resistant infections in a Chicago teaching hospital: implications for antibiotic stewardship, Clin Infect Dis. 49(8) (2009), 1175-1184.

[26] http://www.tufts.edu/med/apua/consumers/personal_home_5_1451036133.pdf (accessed 8-52013).

[27] J. Taylor, M. Hafner, E. Yerushalmi, R. Smith, J. Bellasio, R. Vardavas, T. Bienkowska-Gibbs and J. Rubin, Estimating the economic costs of antimicrobial resistance, Model and Results, 2014. www.rand.org/t/rr911.

[28] R.R. Roberts et al. Hospital and Societal Costs of Antimicrobial-Resistant Infections in a Chicago Teaching Hospital: Implications for Antibiotic Stewardship, Clinical Infectious Diseases 49 (2009), $1175-1184$.

[29] Tackling drug-resistant infections globally: Final report and recommendations the review on antimicrobial resistance chaired by Jim O'Neill.

[30] Centers for Disease Control and Prevention: Antibiotic Resistance Threats in the United States, 2013. http://www.cdc.gov/drugresistance/pdf/ar-threats-2013-508.pdf.

[31] Y.-Y. Liu, Y. Wang, T.R. Walsh et al., Emergence of plasmid-mediated colistin resistance mechanism MCR-1 in animals and human beings in China: A microbiological and molecular biological study, The Lancet Infectious Disease 16(2) (2016), 161-168.

[32] Centers for Disease Control and Prevention. Antibiotic Resistance Threats, 2013.

[33] S. Earnshaw, D.L. Monnet, B. Duncan, J. O’Toole, K. Ekdahl and H. Goossens, European Antibiotic Awareness Day Technical Advisory Committee, European Antibiotic Awareness Day Collaborative Group European antibiotic awareness day 2008: The first Europe-wide public information campaign on prudent antibiotic use; methods and survey activities in participating countries, Eurosurveillance 14 (2009), 418-425.

[34] V.A. Ghazaryan, G. Pyshnik, T. Spasojevic et al., Antibiotic use in Eastern Europe: A cross-national database study in coordination with the WHO Regional Office for Europe, Lancet Infect Dis. 14 (2014), 381-387.

[35] E.I. Broughton, T. Chitashvili, K. Hill, E. Cherkezishvili and N. Shengelia, Commentary: Antibiotic use worldwide, Lancet Infect Dis. 14 (2014), 1179.

[36] N. Sumpradit, P. Chongtrakul, K. Anuwong, S. Pumtong, K. Kongsomboon et al., Antibiotics Smart Use: A workable model for promoting the rational use of medicines in Thailand, Bulletin of the World Health Organization 90 (2012), 905-913. doi: 10.2471/BLT.12.105445.

[37] D. Bhavnani, L. Phatinawin, S. Chantra, S.J. Olsen and J.M. Simmerman, The influence of rapid 
influenza diagnostic testing on antibiotic prescribing patterns in rural Thailand, Int J Infect Dis. 11 (2007), 355-359. doi: 10.1016/j.ijid.2006.09.009. PMID: 17324602.

[38] S. Suttajit, A.K. Wagner, R. Tantipidoke and D. Ross-Degnan, Sitthi-amorn C. Patterns, Appropriateness, and predictors of antimicrobial prescribing for adults with upper respiratory infections in urban slum communities of Bangkok, Southeast Asian J Trop Med Public Health 36 (2005), 489-497. PMID: 15916061.

[39] N. Sumpradit, P. Chongtrakul, K. Anuwong, S. Pumtong, K. Kongsomboon et al., Antibiotics Smart Use: A workable model for promoting the rational use of medicines in Thailand, Bulletin of the World Health Organization 90 (2012), 905-913. doi: 10.2471/BLT.12.105445.

[40] P. Treebupachatsakul, S. Tiengrim and V. Thamlikitkul, Upper respiratory tract Infection in Thai adults: prevalence and prediction of bacterial causes, and effectiveness of using clinical practice guidelines, J Med Assoc Thai 89 (2006), 1178-1186. PMID: 17048427.

[41] N. Sumpradit, P. Chongtrakul, K. Anuwong, S. Pumtong, K. Kongsomboon et al., Antibiotics Smart Use: A workable model for promoting the rational use of medicines in Thailand, Bulletin of the World Health Organization 90 (2012), 905-913. doi: 10.2471/BLT.12.105445.

[42] S. Suttajit, A.K. Wagner, R. Tantipidoke, D. Ross-Degnan and S.A.C. Patterns, Appropriateness, and predictors of antimicrobial prescribing for adults with upper respiratory infections in urban slum communities of Bangkok, Southeast Asian J Trop Med Public Health 36 (2005), 489-497. PMID: 15916061.

[43] R. Panpanich, P. Siviroj, K. Chansung, P. Sanchaisuriya, L. Laohasiriwong, S. Tasaniyom et al., Antibiotics prescription rates for upper respiratory tract infections in Thai National Health Insurance System, J Health Sci 12 (2003), 522-529.

[44] V. Thamlikitkul, Antibiotic dispensing by drug store personnel in Bangkok, Thailand, J Antimicrob Chemother 21 (1998), 125-131. doi: 10.1093/jac/21.1.125. PMID: 3356619.

[45] A. Apisarnthanarak and L.M. Mundy, Comparison of methods of measuring pharmacy sales of antibiotics without prescriptions in Pratumthani, Infect Control Hosp Epidemiol 30 (2009), 11301132.

[46] N. Sumpradit, P. Chongtrakul, K. Anuwong, S. Pumtong, K. Kongsomboon et al., Antibiotics Smart Use: A workable model for promoting the rational use of medicines in Thailand, Bulletin of the World Health Organization 90 (2012), 905-913. doi: 10.2471/BLT.12.105445.

[47] P. Treebupachatsakul, S. Tiengrim and V. Thamlikitkul, Upper respiratory tract Infection in Thai adults: prevalence and prediction of bacterial causes, and effectiveness of using clinical practice guidelines, J Med Assoc Thai 89 (2006), 1178-1186. PMID: 17048427.

[48] Tackling drug-resistant infections globally: Final report and recommendations the review on antimicrobial resistance chaired by Jim O'Neill.

[49] Centers for Disease Control and Prevention. Antibiotic Resistance Threats, 2013.

[50] ibid.

[51] R. Gupta, J.P. Cegielski, M.A. Espinal, M. Henkens and J.Y. Kim, C.S.B. Lambregts-van Weezenbeek, J.W. Lee, M.C. Raviglione, P.G. Suarez and F. Varaine. Increasing transparency in partnerships for health - introducing the Green Light Committee, Tropical Medicine and International Health 7(11) (2002), 970-976.

[52] J.P. Cegielski, E. Kurbatova, M. van der Walt, J. Brand, J. Ershova et al., Multidrug-Resistant Tuberculosis Treatment Outcomes in Relation to Treatment and Initial Versus Acquired SecondLine Drug Resistance, Clinical Infectious Diseases 62(4) (2016), 418-430.

[53] S. Mölstad, O. Cars and S.J. Strama, A Swedish working model for containment of antibiotic resistance, Eurosurveillance 13 (2008), 22-25. PMID: 19021951.

[54] R. Gonzales, K.K. Corbett, S. Wong, J.E. Glazner, E. Deas, B. Leeman-Castillo et al., "Get Smart Colorado": impact of a mass media campaign to improve community antibiotic use, Med Care 46 (2008), 597-605. doi: 10.1097/MLR.0b013e3181653d2e. PMID: 18520314.

[55] B. Huttner, H. Goossens, T. Verheij and S. Harbarth, Characteristics and outcomes of public campaigns aimed at improving the use of antibiotics in outpatients in high-income countries, Lancet $\mathbf{1 0}$ (2010), 17-31. doi: 10.1016/S1473-3099(09)70305-6.

[56] E. Sabuncu, J. David, C. Bernède-Bauduin, S. Pépin, M. Leroy, P.Y. Boëlle et al., Significant reduc- 
tion of antibiotic use in the community after a nationwide campaign in France, 2002-2007, PLoS Med 6 (2009), e1000084. doi: 10.1371/journal.pmed.1000084. PMID: 19492093.

[57] N. Sumpradit, P. Chongtrakul, K. Anuwong, S. Pumtong, K. Kongsomboon et al., Antibiotics Smart Use: A workable model for promoting the rational use of medicines in Thailand, Bulletin of the World Health Organization 90 (2012), 905-913. doi: 10.2471/BLT.12.105445.

[58] https://www.gov.uk/government/news/prime-minister-warns-of-global-threat-of-antibioticresistance.

[59] http://amr-review.org/sites/default/files/160525_Final\%20paper_with\%20cover.pdf.

[60] http://www.whitehouse.gov/the-press-office/2014/09/18/fact-sheet-obama-administration-takesactions-combat-antibiotic-resistan.

[61] http://www.phe.gov/about/BARDA/Pages/default.aspx.

[62] http://www.who.int/phi/implementation/1_infobrief_innovative_medicines_initiative_ND4BB_ models_of_collaboration.pdf.

[63] http://amr-review.org/industry-declaration.

[64] http://amr-review.org/industry-declaration.

[65] p://www.bmg.bund.de/fileadmin/dateien/Downloads/G/G7-Ges.Minister_2015/G7_Health_ Ministers_Declaration_AMR_and_EBOLA.pdf.

[66] http://www.mofa.go.jp/files/000160273.pdf.

[67] http://apps.who.int/gb/ebwha/pdf_files/WHA68/A68_R7-en.pdf.

[68] A.A. Palmu et al., Lancet Infect. Dis. 14 (2014), 205-212.

[69] S.J. Hoffman et al., Strategies for achieving global collective action on antimicrobial resistance, Bull World Health Organ 93 (2015), 867-876. doi: 10.2471/BLT.15.153171.

[70] K.J. Wilby and D. Werry, A review of the effect of immunization programs on antimicrobial utilization, Vaccine 30(46) (2012), 650914.

[71] http://www.niaid.nih.gov/topics/pneumococal/pages/pneumococcaldisease.aspx.

[72] C.A. Lexau et al., Changing Epidemiology of Invasive Pneumococcal Disease among Older Adults in the Era of Pediatric Pneumococcal Conjugate Vaccine, JAMA 294(16) (2005), 2043-2051. doi: 10.1001/jama.294.16.2043.

[73] Advisory Committee on Immunization Practices, Preventing pneumococcal disease among infants and young children. Recommendations of the advisory committee on immunization practices (ACIP), MMWR Recomm Rep 49(RR-9) (2000), 1-35.

[74] K.A. Poehling, T.R. Talbot, M.R. Griffin, A.S. Craig, C.G. Whitney, E. Zell, C.A. Lexau, A.R. Thomas, L.H. Harrison, A.L. Reingold et al., Invasive pneumococcal disease among infants before and after introduction of pneumococcal conjugate vaccine, JAMA 295(14) (2006), 1668-1674; PMID: 16609088; http://dx.doi.org/ 10.1001/jama.295.14.1668.

[75] J.P. Nuorti and C.G. Whitney, Centers for Disease Control and Prevention (CDC). Prevention of pneumococcal disease among infants and children - use of 13-valent pneumococcal conjugate vaccine and 23-valent pneumococcal polysaccharide vaccine - recommendations of the Advisory Committee on Immunization Practices (ACIP), MMWR Recomm Rep 59(RR-11) (2010), 1-18; PMID: 21150868 .

[76] F. Zhou et al., Pediatrics 121 (2008), 253-260.

[77] www.thelancet.com/infection Vol 8 December 2008.

[78] C. Whitney et al., Seminars in Pediatric Infectious Diseases 15(2) (2004), 86-93.

[79] Lancet Infectious Diseases 1 (2001), 85-91.

[80] N Engl J Med 354 (2006), 1455.

[81] L.M. Hampton et al., J. Infect. Dis. 205 (2012), 401-411.

[82] Nature 512 (2014), 14-15.

[83] S. Tomczyk et al., Prevention of Antibiotic-Nonsusceptible Invasive Pneumococcal Disease With the 13-Valent Pneumococcal Conjugate Vaccine, Clinical Infectious Diseases 62(9) (2016), 11191125.

[84] World Health Organization. 2005. Haemophilus influenzae type B (HiB). WHO fact sheet no. 294, December 2005. http://www/who.int/mediacentre/factsheets/fs294/en/index.html. 
[85] S. Tristram, M.R. Jacobs and P.C. Appelbaum, Antimicrobial Resistance in Haemophilus influenzae. CLINICAL MICROBIOLOGY REVIEWS, Apr. 2007, pp. 368-389.

[86] WHO Global Immunization Data available at: http://www.who.int/immunization/monitoring_surve illance/Global_Immunization_Data.pdf?ua=1.

[87] M. Giufrèa et al., Ten years of Hib vaccination in Italy: Prevalence of non-encapsulated Haemophilus influenzae among invasive isolates and the possible impact on antibiotic resistance, Vaccine 29 (2011), 3857-3862.

[88] S. García-Cobos, J. Campos, E. Cercenado, F. Romän, E. Läzaro, M. Pérez-Vázquez et al., Antibiotic resistance in Haemophilus influenzae decreased, except for beta-lactamase-negative amoxicillin-resistant isolates, in parallel with community antibiotic consumption in Spain from 1997 to 2007, Antimicrob Agents Chemother 52(8) (2008), 2760-2766.

[89] ibid.

[90] K.P. Heilmann, C.L. Rice, A.L. Miller, N.J. Miller, S.E. Beekmann, M.A. Pfaller et al., Decreasing prevalence of beta-lactamase production among respiratory tract isolates of Haemophilus influenzae in the United States, Antimicrob Agents Chemother 49 (2005), 2561-2564.

[91] W.T. Jansen, A. Verel, M. Beitsma, J. Verhoef and D. Milatovic, Longitudinal European surveillance study of antibiotic resistance of Haemophilus influenzae, J Antimicrob Chemother $\mathbf{5 8}$ (2006), 873-877.

[92] J.C. Kwong et al., The Effect of Universal Influenza Immunization on Antibiotic Prescriptions: An Ecological Study, Clinical Infectious Diseases 49 (2009), 750-756.

[93] European Commission (2011). Action Plan against the risising threats from antimicrobial resistance COM (2011) 748. Available at: http://ec.europa.eu/dgs/health_consumer/docs/communication_ amr_2011_748_en.pdf and ECDC (2011). Report from the Transatlantic Taskforce on Antimicrobial Resistance. Recommendations for future collaboration between the US and EU. Available at: http://ecdc.europa.eu/en/activities/diseaseprogrammes/tatfar/documents/210911_tatfar_report.pdf.

[94] OMS, Guide pratique sur la prévention des infections nosocomiales, Chapitre X. 2008. WHO/CDS/ CSR/EPH/2002.12.

[95] WHO AMR Report, 2014 - World Health Organization (2014a) Antimicrobial resistance: global report on surveillance 2014. http://www.who.int/drugresistance/documents/surveillancereport/en/.

[96] AMR_report_Web_slide_set. WHO AMR Report, 2014 - World Health Organization (2014a) Antimicrobial resistance: global report on surveillance 2014.

[97] Commission. EU research on antimicrobial resistance: EU projects 2007-2010. Brussels: UC; 2011. Available from: http://ec.europa.eu/research/health/infectious-diseases/antimicrobial-drugresistance/pdf/eu-research-on-antimicrobial-resistance_en.pdf [accessed 13 September 2012].

[98] V. Thamlikitkul, A. Riewpaiboon, P. Prakongsai and S. Limwattananon, Health and economic impacts of antimicrobial resistance in Thailand, J Health Systems Res 6 (2012), 352-360.

[99] Centers for Disease Control and Prevention. Antibiotic Resistance Threats, 2013. 